\title{
Is smoking a predictor of apical periodontitis?
}

\author{
Fabiola-Regina Rodriguez • Babür Taner • \\ Roland Weiger • Clemens Walter
}

Received: 24 May 2012 / Accepted: 21 November 2012 /Published online: 6 December 2012

(C) Springer-Verlag Berlin Heidelberg 2012

\begin{abstract}
Objectives To evaluate the association between cigarette smoking and the frequency of apical periodontitis in female and male patients seeking treatment at the University of Basel (KREBS Project).

Materials and methods This cohort study included fullmouth periapical radiographs of 161 subjects, including 66 current smokers, 26 former smokers and 69 individuals who had never smoked. The periapical region of all teeth was radiographically evaluated using the Periapical Index (PAI) score. Generalised linear mixed-effects models using the logit link were performed.

Results The frequency of apical periodontitis differed based on gender and smoking status. Current male cigarette smokers with $<10$ or $\geq 10$ pack years showed frequencies of apical periodontitis of $12 \%$ and $5.5 \%$, respectively, compared to $3.8 \%$ in individuals who had never smoked. The corresponding data for female smokers were $5.7 \%$ and $7.2 \%$ in smokers with $<10$ or $\geq 10$ pack years, respectively, versus $5.2 \%$ in individuals who had never smoked. The factors "prevalent coronal restoration" $(p<0.001)$, "prevalent root canal treatment" $(p<0.001)$ and "quality of root canal filling" $(p<0.001)$ were significant predictors for apical periodontitis. After adjustment for quality of root canal filling cigarette smoking was not associated with apical periodontitis in current female and male smokers with $<10$ or $\geq 10$ pack years $(p>0.05)$.
\end{abstract}

F.-R. Rodriguez $\cdot$ B. Taner $\cdot$ R. Weiger $\cdot$ C. Walter $(\triangle)$

Department of Periodontology, Endodontology and Cariology,

Dental School, University of Basel, Hebelstrasse 3,

4056, Basel, Switzerland

e-mail: clemens.walter@unibas.ch

C. Walter

Department of Oral Surgery, School of Dentistry,

University of Birmingham, Birmingham, UK
Conclusion Smoking status did not predict apical periodontitis in females and males in this sample group.

Clinical relevance With respect to quality of root canal filling, tobacco use may not be a significant predictor for apical periodontitis.

Keywords Smoking · Tobacco $\cdot$ PAI $\cdot$ Apical periodontitis · Endodontics · Radiology

\section{Introduction}

Tobacco use was considered to be a potential risk factor for apical pathology in two recent systematic reviews $[1,2]$.

However, data regarding an association between tobacco use and apical periodontitis are controversial due to: (a) the different radiographic methods used for the assessment [3, 4], (b) the assessments of apical periodontitis itself [3, 5-7], (c) smoking characteristics and/or categories [3, $5,8-10]$ and/or (d) the inclusion of potential confounding factors $[3,7,11]$.

Several potential pathogenetic mechanisms have been suggested for tobacco induced pathogenesis. The detrimental effect of active and passive tobacco use on the periodontal tissues depends on the number of cigarettes a patient currently smokes, the intensity and duration of smoking (pack years) and/or the time since smoking cessation [12-14]. Tobacco smoking affects the humoral- and cellmediated immunity of the host $[15,16]$, including neutrophil mediated mechanisms leading to oxidative stress [17]. Smoking also affects bone metabolism, resulting in a decreased intestinal uptake of $\mathrm{Ca}^{2+}[18]$ or an increased secretion of the bone resorbing factors $\mathrm{PGE}_{2}$ and IL- $1 \beta$ by monocytes after challenge with lipopolysaccharides [19]. In addition, smokers often exhibit impaired wound healing [20, 21]. The anatomical proximity of the periapical region and the periodontal structures as well as the structural similarity reasons 
the hypothesis of an impact of tobacco on the pulpal diseases and the periapical region.

The prevalence of tobacco use differs among men and women in Switzerland. A study published in 2007 shows that approximately $32 \%$ of men declare themselves to be smokers, whereas the smoking prevalence in women is $26 \%$ [22]. Recent evidence has identified gender differences in socioeconomic status, including education and employment status, and in oral variables such as plaque control and periodontal diseases [4, 23-26]. There are only few data considering a possible gender-specific influence of smoking on apical pathologies $[3,4,7]$. However, the analyses were performed in one gender only, i.e., females [3] or in males [7] or demonstrated a negligible impact of gender on apical periodontitis with respect to smoking status [4]. In the latter study, apical periodontitis was assessed on panoramic radiographs, which probably leads to an overestimation of apical pathologies $[27,28]$. Therefore, the extent to which tobacco use influences pulpal and periapical conditions in females and males remains unclear and was an object of investigation in the present study, launching the KREBS (Klinisch-Radiologische Evaluation einer Basler Subpopulation) Project. The aim of this project is to characterise the population seeking treatment at the University of Basel. Beside the assessment of clinical and radiographic data, socioeconomic data were also collected and considered in the analysis. Several sub-projects, including the (a) analysis of risk factors for tooth loss [29], (b) attachment loss at root canal treated teeth or (c) the quality of root canal fillings in this population are in progress.

We hypothesised an association between apical periodontitis and cigarette smoking. Therefore, the objective of this analysis was to evaluate the association between cigarette smoking and the frequency of apical periodontitis in female and male patients seeking treatment at the University of Basel.

\section{Materials and methods}

Analysis of the patient group

The records of patients from the pool of patients in the Department of Periodontology, Endodontology and Cariology at the University of Basel, Switzerland, were consecutively screened during January 2009 and October 2011. The study was approved by the Ethics Research Committee of the University of Basel, Switzerland (EK: 279/09). Patients who had been treated in the Department of Periodontology, Endodontology and Cariology for the first time between 1998 and 2011 were included if they met the following criteria:

(1) Complete clinical and radiographic examinations were available.
(2) Complete medical records were available.

(3) No invasive dental treatment had been performed prior to the clinical and radiographic examinations performed at the Department of Periodontology, Endodontology and Cariology.

Assessment of risk factors and covariates

Tobacco use was assessed using a standardised tobacco use history data sheet for every patient seen since the year 2006 [30]. The questionnaire asked for detailed information regarding each patient's history of cigarette smoking. Patients who had smoked $<200$ cigarettes in their lifetime were defined as "never smokers". For patients who had attended the clinic before 2006, the tobacco use was calculated according to the tobacco use history data sheet with respect to the time point of clinical/radiographic diagnostics. Current smokers reported the average number of cigarettes consumed. If patients claimed to be former smokers, the time since smoking cessation was determined. The number of pack years was calculated for every patient (by multiplying the number of packs of cigarettes smoked per day - one pack equals 20 cigarettes, historically — by the number of years for which the person had smoked). Patients were asked if they suffered from any systemic diseases, such as diabetes mellitus, heart disease, any chronic diseases or allergies, and if they were currently taking any medications. Due to the large variance, the data were used dichotomously (as systemic disease/medication, prevalent or not prevalent) for statistical analysis. Educational qualifications were expressed as "no graduation from school", "school graduation without any vocational education", "vocational school graduation or currently attending vocational school" or "advanced education (university or polytechnical school)". "Vocational school graduation" was equal to 10 years of school education with 3 years of additional professional training. Patients were also asked if they were engaged in any professional pursuit.

\section{Clinical and radiographic examinations}

All patients were diagnosed and treated according to recently published protocols [21,31]. The data used in this analysis are described briefly as follows. The presence or absence of dental plaque (plaque index [PI]) and gingival inflammation (bleeding index, BI) was assessed by means of two indices $[32,33]$. Probing pocket depth (PPD) was measured to the nearest millimetre at six sites on all teeth using a periodontal probe graded in millimetres. Third molars were excluded, and the number and percentage of the number of sites where PPD $\geq 5 \mathrm{~mm}$ were calculated and used for the analysis. Periapical radiographs of the entire dentition were obtained using 
intraoral dental films (IP 22 Insight Doppel SP size 2; Kodak $\mathrm{GmbH}$, Stuttgart, Germany). A film holder with $90^{\circ}$ angulation (Rinn, Dentsply, Elgin, IL, USA) was used for the parallel technique. All images were acquired with standardised exposure times and X-ray tube voltages (Dental EZ HDX, $65 \mathrm{kV}$, $7 \mathrm{~mA}$; Dental EZ, Hertfordshire, UK). Patient data were transferred to a case report form and then to Microsoft Excel for data processing.

\section{Evaluation of radiographs}

Full-mouth periapical radiographs from 161 patients with a total of 4012 teeth were analysed independently by two examiners (FR, BT). The samples were evaluated using the Periapical Index (PAI) scoring system [34, 35]. Each tooth was categorised as having normal periapical structure (1), small changes in bone structure (2), changes in bone structure with some mineral loss (3), apical periodontitis with well-defined radiolucent areas (4) or severe apical periodontitis with exacerbating features (5) [34]. Multirooted teeth were given the highest PAI score detected at any of the roots. Periapical radiographs were examined in a dark room using a light box and an X-ray magnification viewer $(3.5 \times)$. In addition, the following criteria were analysed:

(1) Missing teeth.

(2) Periapical conditions cannot be judged.

(3) Presence or absence of any coronal restoration (e.g., filling or crown) was determined using a slightly modified classification of Tronstad et al. [36] (any permanent restoration that appeared radiographically without differentiation) as being "intact" or "not intact".

(4) Presence or absence of a root canal filling was determined according to Segura-Egea et al. [37], i.e., teeth were categorised as root filled teeth if the root canals had been filled with a radioopaque material.

(5) Quality of the root canal filling was assessed according to Weiger et al. [38] by evaluating radiographically the length and the density of the root canal filling, separately. Briefly, length of root canal filling was rated using three scores. The apical level of the root canal filling was: (score 1) 0-2 $\mathrm{mm}$ short of the radiographic apex, (2) $>2 \mathrm{~mm}$ short of the radiographic apex, (3) extruded beyond the radiographic apex. The density of the root canal filling was evaluated using two scores: (score 1) "no voids and close adaptation to root canal walls" and (2) "voids or insufficient adaptation to root canal walls". According to López-López et al. [4], quality of root canal filling was considered radiographically "satisfactory" if the root canal filling was rated with score 1 for length and density, otherwise the root canal filling was considered "unsatisfactory".

\section{Calibration of examiners}

The calibration was performed according to a suggestion by Ørstavik et al. [34]. The observers scored 100 reference examples twice according to the PAI criteria. As a second step, calibration was continued with data from 20 patients (587 teeth). Teeth on which the observers did not agree were discussed and evaluated again. As a third step, ten patients with 281 teeth were scored, and questionable scores were discussed until agreement was reached. Finally, five patients with 132 teeth were scored twice by the observers with a break of $20 \mathrm{~min}$ between the evaluations.

\section{Statistical analysis}

To assess the level of agreement between the two examiners, the weighted kappa score $\mathrm{K}$ was calculated [39]. The interexaminer- and intraexaminer-weighted kappa scores $(\kappa)$ for the five patients (with corresponding $95 \%$ confidence intervals [CIs]) were calculated. Weighting was allocated according to the number of readings provided by each patient. Weighted kappa scores $\kappa$ and $95 \%$ CIs were calculated in a Bayesian framework. The details are described by Broemeling [40]. The observers achieved a kappa of 0.77. The intraexaminer weighted kappa values were 0.83 (BT) and 0.91 (FR).

After the calibration procedure, 4,012 teeth from 161 patients were scored according to the aforementioned criteria. PAI scores of 1 and 2 were considered as corresponding to normal periapical conditions; scores $\geq 3$ were considered to indicate apical periodontitis.

Because of the large sample sizes, $t$-tests were performed to compare females and males in the study population. Fisher's exact tests were performed for categorical variables. A test of equal proportions was applied for "gender". The level of significance was $p<0.05$. To predict PAI 3,4 or 5 versus PAI 1 or 2 , generalised linear mixed-effects models using the logit link were performed for both subject-specific (e.g., age, race, smoking groups) and tooth-specific (i.e., coronal restoration, root canal filling, quality of root canal filling) parameters. Odds ratios (OR) and $95 \%$ CIs as well as the corresponding $\mathrm{p}$ values were estimated. In a first step, all parameters were separately analysed by univariate models (data not shown) in order to select the significant parameters for inclusion in a multivariate logistic regression model (Tables 3 and 4). To perform separate analyses for females and males, nested models were executed with subject- and tooth-specific covariates as fixed factors and subject as a random factor. All analyses were performed with the statistical package R (The R Foundation for Statistical Computing Version 2.12.2). 


\section{Results}

Population characteristics

The sample group analysed consisted of 161 participants (80 women and 81 men) with mean ages of $48.0 \pm 14.6$ years (women) and $47.7 \pm 12.5$ years (men). Epidemiologic, socioeconomic and oral clinical patient data are presented in Table 1.

The number of teeth and frequency of teeth with apical periodontitis

Among female current smokers with $<10$ and $\geq 10$ pack year histories, the mean numbers of teeth per subject were 25.8 and 24.1, respectively, compared to 24.6 in females who had never smoked. Males displayed a trend of higher mean numbers of teeth in each smoking category compared to females, with male current smokers with $<10$ pack year histories having 25.9 teeth, current smokers with $\geq 10$ pack year histories having 24.8 teeth and those who had never smoked having 25.5 teeth.

Overall, 4,012 teeth were analysed according to the PAI criteria. After the exclusion of former smokers, 1,751 teeth in females and 1620 teeth in males were included and further analysed in the study (Table 2). Current cigarette smoking in females with $<10$ or $\geq 10$ pack year histories was associated with a higher frequency of apical periodontitis (5.7 \% and $7.2 \%$, respectively) than that found in never smokers $(5.2 \%)$.

Current cigarette smoking with a $<10$ pack year history was associated with a pronounced frequency of apical periodontitis $(12.0 \%)$ in males. The corresponding frequencies for current smokers with $\geq 10$ pack year histories and never smokers were $5.5 \%$ and $3.8 \%$, respectively (Table 2).
Table 1 Demographic data and characteristics of the study population
$P P D$ periodontal probing depth, $P I$ plaque index, $B I$ bleeding index, $S D$ standard deviation

\begin{tabular}{|c|c|c|c|}
\hline Characteristics & Females & Males & $p$ value \\
\hline No. of subjects, $\%(n)$ & $49.7(80)$ & $50.3(81)$ & 1 \\
\hline Age (years), mean $\pm \mathrm{SD}$ & $48.0 \pm 14.6$ & $47.7 \pm 12.5$ & 0.90 \\
\hline Race, \% $(n)$ & & & 0.84 \\
\hline Caucasian & $50.4(66)$ & $49.6(65)$ & \\
\hline Non-Caucasian & $46.7(14)$ & $53.3(16)$ & \\
\hline In profession, $\%(n)$ & & & 0.0019 \\
\hline Yes & $41.6(47)$ & $58.4(66)$ & \\
\hline No & $68.8(33)$ & $31.2(15)$ & \\
\hline Education, $\%(n)$ & & & 0.37 \\
\hline No school graduation & $61.1(11)$ & $38.9(7)$ & \\
\hline School graduation without any vocational education & $57.1(24)$ & $42.9(18)$ & \\
\hline $\begin{array}{l}\text { Vocational school graduation or currently attending } \\
\text { vocational school }\end{array}$ & $56.9(31)$ & $43.1(41)$ & \\
\hline Advanced education (university or polytechnic school) & $48.3(14)$ & $51.7(15)$ & \\
\hline Systemic diseases, \% $(n)$ & & & 1 \\
\hline Yes & $48.9(22)$ & $51.1(23)$ & \\
\hline No & $50.0(58)$ & $50.0(58)$ & \\
\hline Regular medication, \% $(n)$ & & & 0.87 \\
\hline Yes & $50.9(29)$ & $49.1(28)$ & \\
\hline No & $49.0(51)$ & $51.0(53)$ & \\
\hline $\mathrm{N}$ of teeth, mean $\pm \mathrm{SD}$ & $24.6 \pm 3.5$ & $25.2 \pm 3.1$ & 0.22 \\
\hline Oral hygiene, $\mathrm{PI}$, mean $\pm \mathrm{SD}$ & $34.1 \pm 25.1$ & $45.8 \pm 28.2$ & 0.0061 \\
\hline Gingival inflammation, $\mathrm{BI}$, mean $\pm \mathrm{SD}$ & $13.1 \pm 16.6$ & $16.2 \pm 21.9$ & 0.31 \\
\hline $\mathrm{N}$ of sites $\mathrm{PPD} \geq 5 \mathrm{~mm}$, mean $\pm \mathrm{SD}$ & $28.2 \pm 22.4$ & $34.5 \pm 29.7$ & 0.13 \\
\hline$\%$ of sites $\mathrm{PPD} \geq 5 \mathrm{~mm}$, mean $\pm \mathrm{SD}$ & $19.4 \pm 15.3$ & $22.8 \pm 19.0$ & 0.21 \\
\hline Smoking status, \% (n) & & & 0.27 \\
\hline Current & $53.0(35)$ & $47.0(31)$ & \\
\hline$<10$ py & $21.2(14)$ & $15.2(10)$ & \\
\hline$\geq 10$ py & $31.8(21)$ & $31.8(21)$ & \\
\hline Former & $34.6(9)$ & $65.4(17)$ & \\
\hline Never & $52.2(36)$ & $47.8(33)$ & \\
\hline
\end{tabular}


Table 2 Frequency of apical periodontitis according to the PAI score in females (a) and males (b) (numbers were rounded to one decimal place)

\begin{tabular}{|c|c|c|c|c|c|c|c|c|c|c|}
\hline \multirow{2}{*}{$\begin{array}{l}\text { Subjects } \\
(n)\end{array}$} & \multirow{2}{*}{$\begin{array}{l}\text { Teeth } \\
(n)\end{array}$} & \multirow{2}{*}{$\begin{array}{l}\text { Teeth/ } \\
\text { subject } \\
(n)\end{array}$} & \multirow{2}{*}{$\begin{array}{l}\text { Teeth } \\
\text { missing } \\
(n)\end{array}$} & \multirow{2}{*}{$\begin{array}{l}\% \text { teeth not } \\
\text { judgeable }\end{array}$} & \multicolumn{2}{|c|}{ Normal periapical conditions } & \multicolumn{4}{|c|}{ Apical periodontitis } \\
\hline & & & & & $\begin{array}{ll}\% \text { teeth } & \% \text { teeth } \\
\text { with PAI } 1 & \text { with PAI } 2\end{array}$ & $\begin{array}{l}\% \text { teeth } \\
\text { with PAI 1,2 }\end{array}$ & $\begin{array}{l}\% \text { teeth } \\
\text { with PAI } 3\end{array}$ & $\begin{array}{l}\text { \% teeth } \\
\text { with PAI } 4\end{array}$ & $\begin{array}{l}\% \text { teeth } \\
\text { with PAI } 5\end{array}$ & $\begin{array}{l}\% \text { teeth with } \\
\text { PAI } 3,4,5\end{array}$ \\
\hline
\end{tabular}

(a) Smoking status

\begin{tabular}{|c|c|c|c|c|c|c|c|c|c|c|c|c|}
\hline Never & 36 & 884 & 24.6 & 124 & 1.2 & 83.4 & 10.2 & 93.6 & 2.9 & 0.7 & 1.6 & 5.2 \\
\hline Current & 35 & 867 & 24.8 & 113 & 1.4 & 80.5 & 11.3 & 91.8 & 4.1 & 0.4 & 2.3 & 6.7 \\
\hline$<10$ Pack years & 14 & 361 & 25.8 & 31 & 2.7 & 79.9 & 11.7 & 91.6 & 3.7 & 0.3 & 1.8 & 5.7 \\
\hline$\geq 10$ Pack years & 21 & 506 & 24.1 & 82 & 0.6 & 80.9 & 11.0 & 91.9 & 4.4 & 0.5 & 2.6 & 7.2 \\
\hline \multicolumn{13}{|c|}{ (b) Smoking status } \\
\hline Never & 33 & 841 & 25.5 & 83 & 2.0 & 86.5 & 7.8 & 94.3 & 1.5 & 0.4 & 1.9 & 3.8 \\
\hline Current & 31 & 779 & 25.1 & 89 & 1.4 & 79.4 & 11.6 & 91.0 & 3.3 & 1.2 & 3.2 & 7.7 \\
\hline$<10$ Pack years & 10 & 259 & 25.9 & 21 & 2.1 & 70.7 & 15.1 & 85.8 & 4.7 & 1.7 & 5.6 & 12.0 \\
\hline$\geq 10$ Pack years & 21 & 520 & 24.8 & 68 & 1.1 & 83.7 & 9.8 & 93.5 & 2.6 & 0.9 & 2.0 & 5.5 \\
\hline
\end{tabular}

Effect of subject- and tooth-specific covariates

In order to examine the effects of tooth and subject-specific covariates, on the presence of a PAI score of 3, 4, or 5 (apical periodontitis) versus a PAI score of 1 or 2 (normal periapical conditions) generalised linear mixed-effects models using the logit link were performed separately for both gender (Tables 3 and 4). The potential effects of the confounders smoking status, coronal restoration, root canal filling, quality of root canal filling, age, race, profession, education, systemic diseases, medication, oral hygiene, gingival inflammation and periodontal probing depth (see Table 1) were initially analysed by univariate models (data not shown). The results indicate significant differences with respect to gender and/or smoking status. In addition to current smoking (former smoking did not show a significant effect), the potential covariates prevalent coronal restoration, prevalent root canal filling and quality of root canal filling revealed a significant effect on prediction of PAI 3, 4, 5 versus PAI 1, 2 in univariate models. The effect of these factors were further analysed in multivariate generalised linear mixed-effects models using the logit link (Table 3). Quality of root canal filling (Table 4) was separately analysed because of its high correlation to prevalent coronal restoration and prevalent root canal filling.

\section{Model 1}

The presence of a coronal restoration was a predictor of apical periodontitis in female $(\mathrm{OR}=4.16, p<0.001)$ and male $(\mathrm{OR}=3.84, p<0,001)$ patients, when the absence of a coronal restoration was used as a reference (Table 3). In females 308 and in males 208 root canal treated teeth were identified. The pattern of the intraoral distribution of apical periodontitis and the frequency of RCF exhibited similar distributions in either gender (data not shown). In this cohort, the presence of a root canal filling was a strong predictor of apical periodontitis in females $(\mathrm{OR}=9.25, p<0.001)$ and males $(\mathrm{OR}=6.9, p<0.001)$ when compared to the absence of $\mathrm{RCF}$. With respect to a prevalent coronal restoration and a prevalent root canal filling, a differentiation according to pack

Table 3 Model 1

\begin{tabular}{|c|c|c|c|c|c|c|}
\hline \multirow[b]{2}{*}{ Predictor } & \multicolumn{3}{|c|}{ Females } & \multicolumn{3}{|c|}{ Males } \\
\hline & OR & $95 \% \mathrm{CI}$ & $p$ value & OR & $95 \% \mathrm{CI}$ & $p$ value \\
\hline Current smoker $<10$ py vs. never smoker & 1.06 & $0.44-2.52$ & 0.90 & 4.18 & $1.63-10.7$ & 0.0032 \\
\hline Current smoker $\geq 10$ py vs. never smoker & 1.31 & $0.62-2.75$ & 0.48 & 1.78 & $0.82-3.85$ & 0.14 \\
\hline Age $\geq 50$ vs. $<50$ years & 1.01 & $0.53-1.95$ & 0.97 & 1.03 & $0.54-1.97$ & 0.93 \\
\hline RCF yes vs. no & 9.25 & $6.70-12.8$ & $<0.001$ & 6.90 & $4.84-9.83$ & $<0.001$ \\
\hline Restoration yes vs. no & 4.16 & $3.00-5.76$ & $<0.001$ & 3.84 & $2.83-5.21$ & $<0.001$ \\
\hline
\end{tabular}

In a first step, all parameters were separately analysed by univariate models in order to select the significant parameters for inclusion in the multivariate model. To predict PAI 3, 4 or 5 versus PAI 1 or 2, generalised linear mixed-effects models using the logit link were performed for both subject-specific (e.g., age, race, smoking groups) and tooth-specific (i.e., prevalent coronal restoration and root canal filling) parameters. Odds ratios and $95 \%$ CIs as well as the corresponding $p$ values were estimated. To perform separate analyses for females and males, nested models were executed with subject-and tooth-specific covariates as fixed factors and subject as a random factor. All analyses were performed with the statistical package R (The R Foundation for Statistical Computing Version 2.12.2) 
Table 4 Model 2

\begin{tabular}{|c|c|c|c|c|c|c|}
\hline \multirow[b]{2}{*}{ Predictor } & \multicolumn{3}{|c|}{ Females } & \multicolumn{3}{|c|}{ Males } \\
\hline & OR & $95 \% \mathrm{CI}$ & $p$ value & OR & $95 \% \mathrm{CI}$ & $p$ value \\
\hline Current smoker $<10$ py vs. never smoker & 1.42 & $0.37-5.53$ & 0.61 & 2.79 & $0.69-11.3$ & 0.15 \\
\hline Current smoker $\geq 10$ py vs. never smoker & 0.95 & $0.29-3.08$ & 0.93 & 1.00 & $0.25-4.01$ & 1.0 \\
\hline Age $\geq 50$ vs. $<50$ & 0.75 & $0.27-2.11$ & 0.59 & 1.50 & $0.49-4.60$ & 0.48 \\
\hline RCF unsatisfactory vs. satisfactory & 4.25 & $1.84-9.82$ & $<0.001$ & 1.72 & $0.67-4.41$ & 0.26 \\
\hline
\end{tabular}

To predict PAI 3, 4 or 5 versus PAI 1 or 2, generalised linear mixed-effects models using the logit link were performed for both subject-specific and tooth-specific (i.e., quality of root canal treatment) parameters. Odds ratios and $95 \%$ CIs as well as the corresponding $p$ values were estimated.

years was performed and revealed, that a history of $<10$ pack years in male current smokers could significantly predict apical periodontitis $(\mathrm{OR}=4.18, p=0.0032)$ when never smokers were used as the reference. In male current smokers with a tobacco use history $\geq 10$ pack years $(\mathrm{OR}=1.78, p=0.14)$ and in female smokers with a history of either $<10(\mathrm{OR}=1.06$, $p=0.90)$ or $\geq 10$ pack years $(\mathrm{OR}=1.31, \mathrm{p}=0.48)$, apical periodontitis could not be significantly predicted when never smokers were used as the reference.

\section{Model 2}

In addition, the effect of the possible confounder quality of the root canal filling rated as "unsatisfactory" or "satisfactory" was analysed in a separate model. Quality of root canal filling was a significant predictor of apical periodontitis in females $(\mathrm{OR}=4.25, p<0.001)$ but not in males $(\mathrm{OR}=1.72, p=0.26)$. In this model, taking quality of root canal filling into account, current smoking with $<10$ or $\geq 10$ pack years did not significantly $(p>0.05)$ predict apical periodontitis in females or males (Table 4).

\section{Discussion}

The present study was performed in patients seeking dental treatment at the University of Basel to analyse the association between cigarette smoking and radiographically assessed periapical conditions with respect to gender. As known from other medical fields, tobacco use induces alterations in the metabolism of the vasculature, connective tissue and bone. The immunity of the host is severely affected by tobacco use. Due to the tobacco-induced alterations, the physiological balance between anabolic and catabolic mechanisms is disrupted [13, 15-17, 41]. In addition, recent evidence suggests gender specific differences in the prevalence of tobacco use, in socioeconomic status, including education and employment status, and in oral variables such as plaque control and periodontal diseases $[4,22-26]$.

We therefore hypothesised a possible gender specific impact of tobacco use on the periapical tissues. An observation of this study was a higher frequency of apical periodontitis for current smokers of both genders compared with never smokers. The frequency of apical periodontitis varied based on gender and smoking status and the difference between the smoking categories was more pronounced in males compared to females. Obviously, the association of smoking status and apical periodontitis is attenuated by the covariates taken into the statistical model (Tables 3 and 4). However, after adjustment for quality of root canal filling cigarette smoking status was not significantly associated with apical periodontitis in current female and male smokers with $<10$ or $\geq 10$ pack years (Table 3 ).

In a recent systematic review, the association between cigarette smoking and apical periodontitis was analysed after the identification of nine relevant studies [2]. In this literature review, five $[3,5,8,10,11]$ out of six cross-sectional studies showed an association between apical periodontitis and cigarette smoking in different populations. In addition, one longitudinal study demonstrated an increased risk for root canal treatment in current smokers [7]. A large heterogeneity among the studies was obvious, and the results were contradictory to some extent (for details, see Walter et al. [2]). Therefore, the authors requested further evidence for the analysis of any possible association between tobacco use and apical periodontitis. They suggested the following parameters for further research:

(1) A defined categorisation of the history of tobacco use, including an assessment of pack years and the definition of current, former and never smokers

(2) Periapical radiographs for the assessment of apical periodontitis

(3) The PAI scoring system 
(4) Analysis of data, taking into account several confounding factors, including subject- and tooth-specific parameters

A dose-response relationship has been documented for the effects of tobacco use on periodontal tissues [12, 13, 42]. Therefore, a broad categorisation of tobacco use yields varying results, as shown in studies on the association between apical periodontitis and tobacco use [3, 5, 8-10]. In the current study, smokers were categorised as follows: (a) never smokers, former smokers and current smokers and (b) according to the number of pack years (for current smokers). Interestingly, gender-specific differences in the frequency of apical periodontitis due to tobacco use have not been previously reported. However, tobacco use did not predict apical periodontitis in females and males, when quality of root canal treatment was taken into account. Nevertheless, the data may be interpreted with care due to the characteristics of this Swiss cohort and the number of patients analysed in this study.

Recently, differences in oral health were found between males and females in a large cohort study in East Germany (Study of Health in Pomerania [SHIP]) [23]. The authors questioned why the women were periodontally healthier but had fewer teeth than men. There is evidence that women have a higher frequency of medical attendance and generally higher health awareness [23, 24]. In addition, Meisel and coworkers [23] found that the women in the study had a lower socioeconomic status than the men. The higher rate of medical attendance in females and the higher socioeconomic status in males may affect decision-making regarding the extraction of a compromised tooth, probably leading to fewer extractions in males. In the patient group in this study, significantly fewer women were engaged in a professional pursuit, the oral hygiene was significantly better in females and there was a higher prevalence of root canal treated teeth (Table 1). These results are consistent with those of a German cohort study to a large extent [23]. Gender differences regarding the frequency of apical periodontitis were documented in this cohort (Tables 1, 2, 3 and 4).

The outcome of endodontic treatment and/or the frequency of apical periodontitis may be affected by several covariates, including systemic health $[11,43]$, socioeconomic parameters [44] or oral variables [45, 46]. A further possible confounder, in particular in woman with osteoporosis, might be the bone mineral density, due to their suggested impact on alveolar bone texture $[47,48]$. In this study on patients seeking dental treatment at the University of Basel, patient characteristics, age, race, education, prevalence of systemic diseases and regular medication were (a) similar among women and men and (b) seemed to not be predictive of apical periodontitis. Marending and co-workers [43] analysed the impact of an altered immune system, assessed as various prevalent systemic diseases, on the outcome of endodontic treatment. In this study, the subject's immune system was a significant predictor of the outcome of the endodontic treatment [43]. In addition, a recent study on hypertensive patients demonstrated a very strong positive association with an OR of 16.8 between endodontic variables and tobacco use [11]. The results of the current analysis of patients at the University of Basel are contradictory to this finding as they do not demonstrate any prevalent systemic disease to be a predictor of apical periodontitis in either gender. However, a possible explanation for this finding may be the different definitions of systemic diseases used in both studies. Whereas Marending et al. [43] and Segura-Egea et al. [11] focused on severe systemic conditions, a broader categorisation was chosen in the current analysis due to the large variability of systemic diseases in the patient group. Further study is required regarding the possible association between systemic factors and endodontic variables.

The current study revealed the presence of coronal restoration, a root canal filling and the quality of the root canal filling to be important predictors of apical periodontitis (Tables 3 and 4). This finding is in agreement with the evidence reported by Bergström et al. [49], $\mathrm{Ng}$ et al. [45], López-López et al. [4] and Peciuliene et al. [50].

\section{Conclusions}

In conclusion, the frequency of apical periodontitis differed between females and males and between current and never smokers. Several covariates affect the association of smoking status and apical periodontitis. However, after adjustment for quality of root canal filling cigarette smoking was not significantly associated with apical periodontitis in current female and male smokers.

Acknowledgments Parts of this research were conducted by F.R Rodríguez in partial fulfilment of the requirements for an MD degree from the University of Basel, Switzerland. The authors gratefully acknowledge H. Hecker, N. Paganoni and E. Flückiger for their kind contribution to the manuscript. We thank Prof. Dr. Dr. Thomas Dietrich for the helpful statistics counselling and A. Schötzau and U. Simmen (Schötzau \& Simmen, Basel, Switzerland) for statistical analysis.

Conflict of interest The KREBS Project is partly supported by two unrestricted grants from the MS-Dental Forum (Busswil, Switzerland) and the Swiss National Program to promote Tobacco Use Prevention and Cessation (Bern, Switzerland).

\section{References}

1. Duncan HF, Pitt Ford TR (2006) The potential association between smoking and endodontic disease. Int Endod J 39:843-854 
2. Walter C, Rodriguez FR, Taner B, Hecker H, Weiger R (2012) Association of tobacco use and periapical pathosis - a systematic review. Int Endod J. doi:10.1111/j.1365-2591.2012.02072.x

3. Frisk F, Hakeberg M (2006) Socio-economic risk indicators for apical periodontitis. Acta Odontol Scand 64:123-128

4. López-López J, Jané-Salas E, Estrugo-Devesa A, CastellanosCosano L, Martín-González J, Velasco-Ortega E, Segura-Egea JJ (2012) Frequency and distribution of root-filled teeth and apical periodontitis in an adult population of Barcelona, Spain. Int Dent J 62:40-46

5. Aleksejuniene J, Eriksen HM, Sidaravicius B, Haapasalo M (2000) Apical periodontitis and related factors in an adult Lithuanian population. Oral Surg Oral Med Oral Pathol Oral Radiol Endod 90:95-101

6. Bergström J, Babcan J, Eliasson S (2004) Tobacco smoking and dental periapical condition. Eur J Oral Sci 112:115-120

7. Krall EA, Abreu Sosa C, Garcia C, Nunn ME, Caplan DJ, Garcia RI (2006) Cigarette smoking increases the risk of root canal treatment. J Dent Res 85:313-317

8. Kirkevang LL, Wenzel A (2003) Risk indicators for apical periodontitis. Community Dent Oral Epidemiol 31:59-67

9. Kirkevang LL, Vaeth M, Horsted-Bindslev P, Bahrami G, Wenzel A (2007) Risk factors for developing apical periodontitis in a general population. Int Endod J 40:290-299

10. Segura-Egea JJ, Jimenez-Pinzon A, Rios-Santos JV, VelascoOrtega E, Cisneros-Cabello R, Poyato-Ferrera MM (2008) High prevalence of apical periodontitis amongst smokers in a sample of Spanish adults. Int Endod J 41:310-316

11. Segura-Egea JJ, Castellanos-Cosano L, Velasco-Ortega E, RíosSantos JV, Llamas-Carreras JM, Machuca G, López-Frías FJ (2011) Relationship between smoking and endodontic variables in hypertensive patients. J Endod 37:764-767

12. Tomar SL, Asma S (2000) Smoking-attributable periodontitis in the United States: findings from NHANES III. National Health and Nutrition Examination Survey. J Periodontol 71:743-751

13. Warnakulasuriya S, Dietrich T, Bornstein MM et al (2010) Oral health risks of tobacco use and effects of cessation. Int Dent $\mathrm{J}$ 60:7-30

14. Walter C, Krall EA, Dietrich T (2012) Active and passive smoking - assessment issues in periodontal research. Periodontol 2000 58:84-92

15. Palmer RM, Wilson RF, Hasan AS, Scott DA (2005) Mechanisms of action of environmental factors - tobacco smoking. J Clin Periodontol 32:180-195

16. Ryder MI (2007) The influence of smoking on host response in periodontal infections. Periodontol 2000 (43):267-277

17. Matthews JB, Chen FM, Milward MR, Ling MR, Chapple IL (2012) Neutrophil superoxide production in the presence of cigarette smoke extract, nicotine and cotinine. J Clin Periodontol 39:626-634

18. Krall EA, Dawson-Hughes B (1999) Smoking increases bone loss and decreases intestinal calcium absorption. J Bone Miner Res $14: 215-220$

19. Payne JB, Johnson GK, Reinhardt RA, Dyer JK, Maze CA, Dunning DG (1996) Nicotine effects on PGE2 and IL-1 beta release by LPStreated human monocytes. J Periodontal Res 31:99-104

20. Silverstein P (1992) Smoking and wound healing. Am J Med 93:22S-24S

21. Walter C, Krastl G, Weiger R (2008) Step-wise treatment of two periodontal-endodontic lesions in a heavy smoker. Int Endod $\mathrm{J}$ 41:1015-1023

22. Forey B, Hamling J, Hamling J, Lee P (2007) International smoking statistics: a collection of worldwide historical data. Switzerland. Web Edition, 1-40

23. Meisel P, Reifenberger J, Haase R, Nauck M, Bandt C, Kocher T (2008) Women are periodontally healthier than men, but why don't they have more teeth than men? Menopause 15:270-275
24. Ansari WE, Stock C, Snelgrove S et al (2011) Feeling healthy? A survey of physical and psychological wellbeing of students from seven universities in the UK. Int J Environ Res Public Health 8:1308-1323

25. Zitzmann NU, Zemp E, Weiger R, Lang NP, Walter C (2011) Does a clinician's sex influence treatment decisions? Int J Prosthodont 24:507-514

26. McKay JC, Quiñonez CR (2012) The feminization of dentistry: implications for the profession. J Can Dent Assoc 78:c1

27. Ridao-Sacie C, Segura-Egea JJ, Fernández-Palacín A, BullónFernández P, Ríos-Santos JV (2007) Radiological assessment of periapical status using the periapical index: comparison of periapical radiography and digital panoramic radiography. Int Endod J 40:433-440

28. Rohlin M, Kullendorff B, Ahlquist M, Henrikson CO, Hollender L, Stenström B (1989) Comparison between panoramic and periapical radiography in the diagnosis of periapical bone lesions. Dentomaxillofac Radiol 18:151-155

29. Rodriguez F, Weiger R, Walter C (2012) Lower education level as a risk factor for tooth loss in a Swiss population (Krebs-cohort). Europerio7, 6.6.-9.6.2012, Vienna, Austria, J Clin Periodontol 2012 Issue Supplement s13; 39:81 (PO 266)

30. Ramseier CA, Bornstein MM, Saxer UP, Klingler K, Walter C (2007) Tobacco use prevention and cessation in the dental practice. Schweiz Monatsschr Zahnmed 117:253-278

31. Walter C, Kaner D, Berndt DC, Weiger R, Zitzmann NU (2009) Three-dimensional imaging as a pre-operative tool in decision making for furcation surgery. J Clin Periodontol 36:250-257

32. O'Leary TJ, Drake RB, Naylor JE (1972) The plaque control record. J Periodontol 43:38

33. Ainamo J, Bay I (1975) Problems and proposals for recording gingivitis and plaque. Int Dent J 25:229-235

34. Ørstavik D, Kerekes K, Eriksen HM (1986) The periapical index: a scoring system for radiographic assessment of apical periodontitis. Dent Traumatol 2:20-34

35. Ørstavik D (1988) Reliability of the periapical index scoring system. Scand J Dent Res 96:108-111

36. Tronstad L, Asbjornsen K, Doving L, Pedersen I, Eriksen HM (2000) Influence of coronal restorations on the periapical health of endodontically treated teeth. Endod Dent Traumatol 16:218-221

37. Segura-Egea JJ, Jiménez-Pinzón A, Ríos-Santos JV, VelascoOrtega E, Cisneros-Cabello R, Poyato-Ferrera M (2005) High prevalence of apical periodontitis amongst type 2 diabetic patients. Int Endod J 38:564-569

38. Weiger R, Hitzler S, Hermle G, Löst C (1997) Periapical status, quality of root canal fillings and estimated endodontic treatment needs in an urban German population. Endod Dent Traumatol 13:69-74

39. Everitt BS (1968) Moments of statistics kappa and weighted kappa. Br J Math Stat Psychol, 97-103

40. Broemeling LD (2007) Bayesian biostatistics and diagnostic medicine. Chapman and Hall/CRC, p 119

41. Johnson GK Gutmiller JM (2007) The impact of cigarette smoking on periodontal disease and treatment. Periodontol 2000 44:178194

42. Dietrich T, Hoffmann K (2004) A comprehensive index for the modeling of smoking history in periodontal research. J Dent Res 83:859-863

43. Marending M, Peters OA, Zehnder M (2005) Factors affecting the outcome of orthograde root canal therapy in a general dentistry hospital practice. Oral Surg Oral Med Oral Pathol Oral Radiol Endod 99:119-124

44. Enberg N, Wolf J, Ainamo A, Alho H, Heinälä P, LenanderLumikari M (2001) Dental diseases and loss of teeth in a group of Finnish alcoholics: a radiological study. Acta Odontol Scand 59:341-347 
45. Ng YL, Mann V, Rahbaran S, Lewsey J, Gulabivala K (2008) Outcome of primary root canal treatment: systematic review of the literature - Part 2. Influence of clinical factors. Int Endod J 41:6-31

46. Rees JS, Thomas M, Naik P (2011) A prospective study of the prevalence of periapical pathology in severely worn teeth. Dent Update 38:24-26

47. Lee BD, White SC (2005) Age and trabecular features of alveolar bone associated with osteoporosis. Oral Surg Oral Med Oral Pathol Oral Radiol Endod 100:92-98
48. Jonasson G, Jonasson L, Kiliaridis S (2007) Skeletal bone mineral density in relation to thickness, bone mass, and structure of the mandibular alveolar process in dentate men and women. Eur J Oral Sci 115:117-123

49. Bergström J, Eliasson S, Ahlberg KF (1987) Periapical status in subjects with regular dental care habits. Community Dent Oral Epidemiol 15:236-239

50. Peciuliene V, Rimkuviene J, Maneliene R, Ivanauskaite D (2006) Apical periodontitis in root filled teeth associated with the quality of root fillings. Stomatologija 8:122-126 